\title{
Study on the Production of Bonded Magnet NdFeB and Polyvinyl Butyral
}

\author{
Mareanus Mendrofa ${ }^{1}$, Perdinan Sinuhaji ${ }^{*}$, Muljadi $^{2,3 *}$, Priyo Sardjono ${ }^{2}$, \\ Achmad Maulana Soehada Sebayang, Anggito P. Tetuko ${ }^{2}$, Nining ${ }^{3}$, Eko \\ Arief Setiadi $^{2}$, Lukman Nurdiansyah ${ }^{2}$, Martha Rianna ${ }^{1}$, Masno Ginting ${ }^{2}$ \\ and Perdamean Sebayang ${ }^{2}$ \\ ${ }^{1}$ Department of Physics, Faculty of Mathematics and Natural Science, Universitas Sumatera Utara \\ 20155, Indonesia \\ ${ }^{2}$ Research Center for Physics, Indonesian Institute of Sciences (LIPI), Tangerang Selatan, Banten 15314, \\ Indonesia \\ ${ }^{3}$ Department of Mechanical Engineering, Universitas Pamullang, Tangerang Selatan 15417, Indonesia
}

\begin{abstract}
. bonded magnet is composite magnet material made by mixing magnetic powder with non-magnetic binder. The process in manufacturing bonded magnet $\mathrm{NdFeB}$ made by mixing powder of neodymium iron boron $(\mathrm{NdFeB})$ commercial type MQP-B with a polyvinyl butyral powder using a glass beaker. The comparisons of variation in composing $\mathrm{NdFeB}$ magnets powders with a binder of PVB (\% weight) are 98:2, 96:4, 94:6 and 93:7 of 8 grams from total mass of the sample. After mixing the powder, it is molded by using a compression molding method with 8 tons pressure for 20 minutes at curing temperature $160^{\circ} \mathrm{C}$. The molded samples are conducted by characterizing the physical properties which include measurement of density, microstructure analysis using SEM-EDX and magnetic properties which include measurement of the magnetic field strength using a Gaussmeter and hysteresis curve using VSM. The result of the study shows that the addition of and binder PVB in bonded magnet $\mathrm{NdFeB}$ causes a decrease in the density and magnetic field strength. The best result of density and magnetic field in the manufacture of bonded magnets is obtained by the addition of $2 \%$ binder of $5.66 \mathrm{~g} / \mathrm{cm}^{3}$ and strong magnetic field of $1862.4 \mathrm{G}$. the score of $\mathrm{Mr}=72.86 \mathrm{emu} / \mathrm{g}, \mathrm{Ms}=103 \mathrm{emu} / \mathrm{gram}, \mathrm{Hc}=8.490 \mathrm{KOe}$ and $\mathrm{BH}_{\max }=5.1$ MGOe was obtained on the addition of PVB $2 \%$.
\end{abstract}

Keyword: bonded magnets $\mathrm{NdFeB}$, polyvinyl butyral binder, physical properties and magnetic.

Received 28 October 2019 | Revised [25 November 2019] | Accepted [14 February 2020]

\section{Introduction}

The need for magnetic materials has increased rapidly in recent decades. This dramatic development in the magnetic field has occurred since the discovery of rare earth permanent magnets such as $\mathrm{NdFeB}, \mathrm{RECo}$, and REFeB. Currently permanent magnet materials are widely used in various applications to convert electrical energy into mechanical energy or vice versa. Three important properties that describe the performance of permanent magnets are magnetic

*Corresponding author at: Jl. Bioteknologi No.1 Kampus USU, Medan, Indonesia, 20155

E-mail address: perdinan@usu.ac.id; mulj004@lipi.go.id 
induction of remanence $(\mathrm{Br})$, coercivity $(\mathrm{Hc})$, and maximum energy product (BHmax) [1]. Until now, in Indonesia, magnet products, especially permanent magnets, on the market are still 100\% import based. The need for permanent magnets in Indonesia is very high and puts Indonesia into the world's number 2 market [2].

In general, Neodymium Iron Boron $(\mathrm{NdFeB})$ magnets are known as rare earth magnets. Manget Neodymium Iron Boron $(\mathrm{NdFeB})$ is an alloy that comes from the Lanthanide group in the periodic system of elements. Neodymium Iron Boron $(\mathrm{NdFeB})$ magnets are earth magnets made of an alloy of neodymium, iron and boron to form a tetragonal Nd2Fe14B crystal structure. Developed in 1982 by General Motors and Sumitomo Special Metals, NdFeB magnets are the most powerful permanent magnets created [3]. $\mathrm{NdFeB}$ magnets are third generation permanent magnet materials made from rare earths which have a large product energy, and have become an important part of everyday human life. $\mathrm{NdFeB}$ magnets are widely applied to various equipment such as electric motors, speakers, $\mathrm{CD}$ players, microwave ovens. Other applications of magnetic components are also found in instrumentation equipment, production equipment and in research laboratories. However, the magnetic contribution is often ignored because this component is already embedded in a device and cannot be seen. In fact, the need for these components varies depending on the use and function of a device [4].

The application of various techniques in the bonded magnet production process, provides the possibility for the use of various magnetic powders in combination with different polymeric materials as binding agents. The development of bonded technology, exploring the possible applications of various types of magnetic powders and polymer matrices, examining the effect of these polymers, for example the effect on process parameters, to achieve optimal mechanical and magnetic capacities is the focus of research on bonded magnets in recent years [5]. Polyvinyl Butyral (PVB) is a resin that is widely used as a binder and has the chemical formula $\mathrm{C}_{8} \mathrm{H}_{14} \mathrm{O}_{2}$. Polyvinyl Butyral resin is used in various applications including in ceramic engineering (temporary) as an adhesive [6].

\section{Materials and Methods}

The process of making a bonded magnet is carried out using NdFeB type MQP-B magnetic powder and a polyvinyl butyral binder. NdFeB magnetic powder and PVB binder were weighed with each composition variation from a total mass of 8 grams, then the two powders were mixed and compacted using a hydraulic press. The samples from the compaction were carried out by characterizing the physical properties and characterizing the magnetic properties. The flow of work carried out in the manufacture of $\mathrm{NdFeB}$ bonded magnets is shown in Figure 1. 


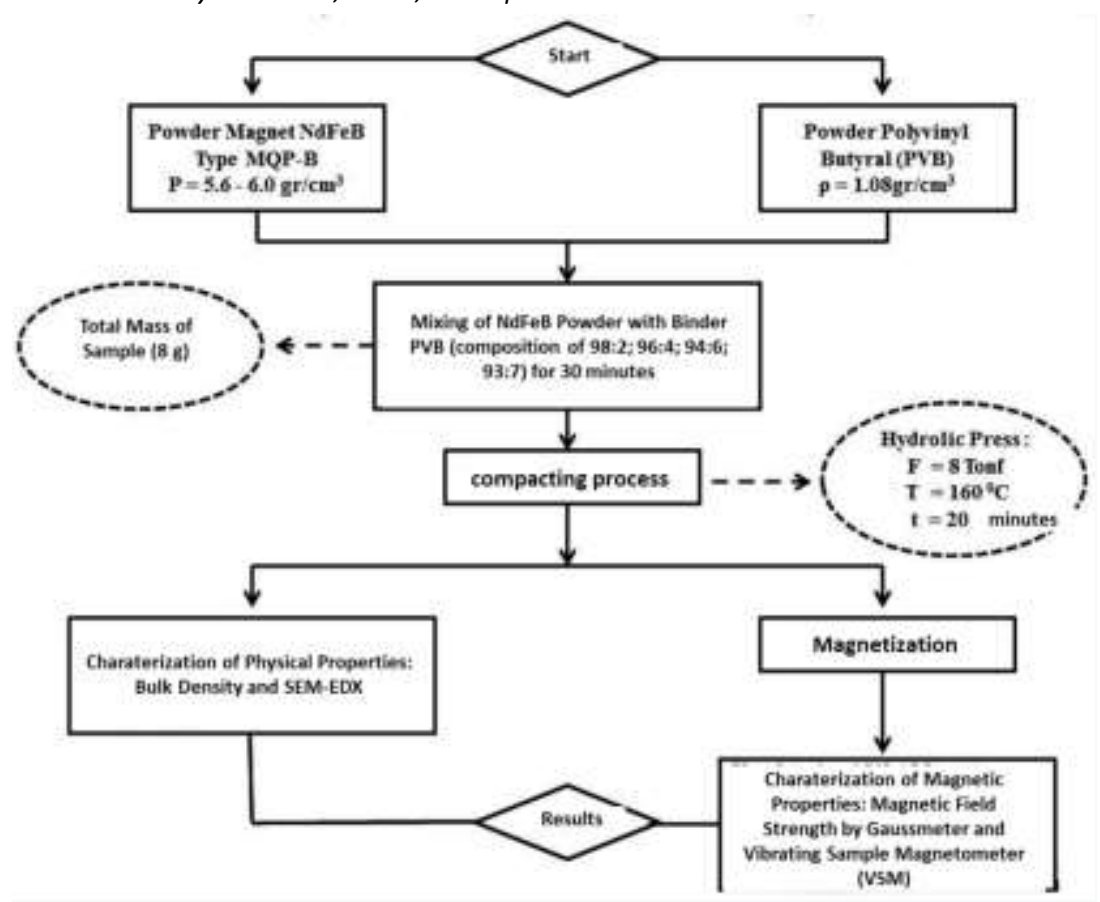

Figure 1. Flow of the bonded manufacturing process $\mathrm{NdFeB}$ magnets

\section{Result and Discussion}

\subsection{Physical Characterization}

\section{A. Density Analysis}

The density measurement is determined by the volume dimension measurement method. From the test results and the calculation of the magnitude of the density on the NdFeB bonded magnet of a sample with various variations in the composition of the binder material (wt \%) are shown as in Figure 2.

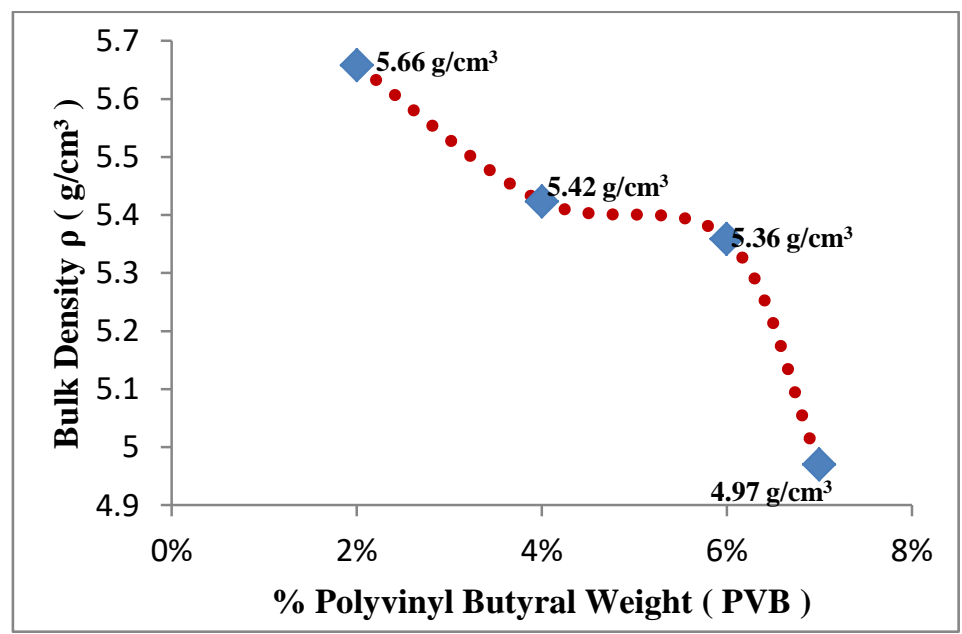

Figure 2. Graph of the relationship between weight\% Polyvinyl Butyral (PVB) to the density value of the $\mathrm{NdFeB}$ bonded magnet 
Figure 2 shows that the variation in the composition of the Polyvinyl Butyral (PVB) binder greatly affects the density of the $\mathrm{NdFeB}$ bonded magnet. The value of the density will tend to decrease with increasing the amount of polymer composition in the $\mathrm{NdFeB}$ bonded magnet. This decrease in density indicates the occurrence of a density reduction process in the sample due to the effect of the polymer mixture on the NdFeB bonded magnet material. The result of high density values in bonded magnet materials is due to the even distribution of $\mathrm{NdFeB}$ magnetic powder in the polymer matrix and the small number of pores that occur [7].

B. Microstructural Analysis

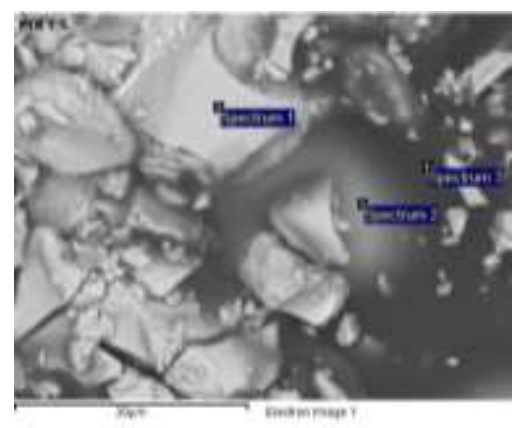

Figure 3. Results of Secondary Electron analysis photos of $\mathrm{NdFeB}$ bonded magnet pellet sample with $2 \%$ binder

Table 1. Element quantitative of $\mathrm{NdFeB}$ powder after addition of $2 \%$ polyvinyl butyral (PVB) binder to spectrum 1

\begin{tabular}{ccc}
\hline Element & $\% \mathrm{Wt}$ & $\% \mathrm{At}$ \\
\hline $\mathrm{C}$ & 8.84 & 33.65 \\
$\mathrm{O}$ & 2.03 & 5.81 \\
$\mathrm{Fe}$ & 60.19 & 49.26 \\
$\mathrm{Co}$ & 4.60 & 3.57 \\
$\mathrm{Nd}$ & 24.33 & 7.71 \\
\hline
\end{tabular}

Table 2. Element quantitative of $\mathrm{NdFeB}$ powder after addition of $2 \%$ polyvinyl butyral (PVB) binder to spectrum 2

\begin{tabular}{ccc}
\hline Element & $\% \mathrm{Wt}$ & $\% \mathrm{At}$ \\
\hline $\mathrm{C}$ & 6.76 & 29.21 \\
$\mathrm{O}$ & 0.47 & 1.54 \\
$\mathrm{Fe}$ & 59.26 & 55.06 \\
$\mathrm{Co}$ & 4.11 & 3.62 \\
$\mathrm{Nd}$ & 29.39 & 10.57 \\
\hline
\end{tabular}


Table 3. Element quantitative of $\mathrm{NdFeB}$ powder after addition of $2 \%$ polyvinyl butyral (PVB) binder to spectrum 3

\begin{tabular}{ccc}
\hline Element & $\% \mathrm{Wt}$ & $\% \mathrm{At}$ \\
\hline $\mathrm{C}$ & 22.42 & 60.64 \\
$\mathrm{O}$ & 2.65 & 5.39 \\
$\mathrm{Fe}$ & 44.62 & 25.96 \\
$\mathrm{Co}$ & 3.64 & 2.01 \\
$\mathrm{Nd}$ & 26.67 & 6.01 \\
\hline
\end{tabular}

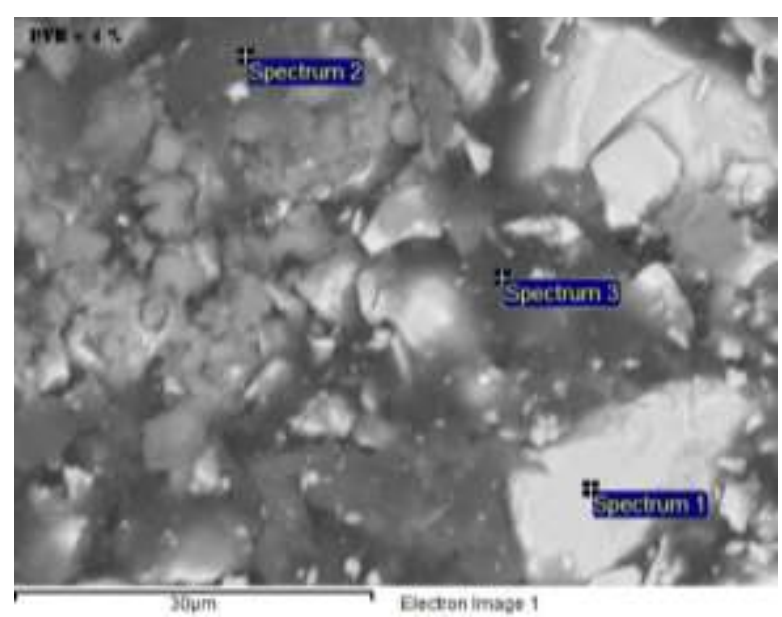

Figure 4. Secondary Electron analysis photos of samples of $\mathrm{NdFeB}$ bonded magnet pellets with $4 \%$ PVB binder

Table 4. Element quantitative of $\mathrm{NdFeB}$ powder after addition of $4 \%$ polyvinyl butyral (PVB) binder to spectrum 1

\begin{tabular}{ccc}
\hline Element & $\% \mathrm{Wt}$ & $\% \mathrm{At}$ \\
\hline $\mathrm{C}$ & 7.43 & 29.51 \\
$\mathrm{O}$ & 2.15 & 6.42 \\
$\mathrm{Fe}$ & 60.83 & 51.95 \\
$\mathrm{Co}$ & 4.90 & 3.96 \\
$\mathrm{Zn}$ & 0.03 & 0.02 \\
$\mathrm{Nd}$ & 24.72 & 8.17 \\
\hline
\end{tabular}

Table 5. Element quantitative of $\mathrm{NdFeB}$ powder after addition of $4 \%$ polyvinyl butyral (PVB) binder to spectrum 2

\begin{tabular}{ccc}
\hline Element & $\% \mathrm{Wt}$ & $\% \mathrm{At}$ \\
\hline $\mathrm{C}$ & 65.92 & 81.26 \\
$\mathrm{O}$ & 15.85 & 14.67 \\
$\mathrm{Si}$ & 0.10 & 0.05 \\
$\mathrm{Cl}$ & 0.23 & 0.09 \\
$\mathrm{Fe}$ & 11.94 & 3.17 \\
$\mathrm{Nd}$ & 4.99 & 0.51 \\
\hline
\end{tabular}


Table 6. Element quantitative of $\mathrm{NdFeB}$ powder after addition of $4 \%$ polyvinyl butyral (PVB)

binder to spectrum 3

\begin{tabular}{ccc}
\hline Element & $\% \mathrm{Wt}$ & $\% \mathrm{At}$ \\
\hline $\mathrm{C}$ & 66.67 & 82.63 \\
$\mathrm{O}$ & 14.20 & 13.22 \\
$\mathrm{Fe}$ & 12.51 & 3.34 \\
$\mathrm{Co}$ & 0.89 & 0.23 \\
$\mathrm{Nd}$ & 5.73 & 0.59 \\
\hline
\end{tabular}

Based on the results of surface morphology using SEM, as in the picture above shows that the Polyvinyl Butyral (PVB) binder on the NdFeB magnet is partly spread or evenly distributed across the surface of the pellet sample. As in Figure 3, the PVB binder is 2\%, where in the sample it can be seen that the dark polymer matrix is uneven throughout the surface of the dark gray Nd-Fe-B particles. Whereas in Figure 4 the 4\% PVB binder shows that the polymer matrix is evenly distributed throughout the surface of the Nd-Fe-B particles. Although the Nd-Fe-B particles still have variations in size and shape, it is clear that the polymer that is between the Nd-Fe-B powder adheres well. Even particle distribution and good adhesion between the NdFe-B particles and the polymer matrix are important to show the quality and strength of a bonded magnet.

The EDX test results show the presence of oxygen $(\mathrm{O})$ in the sample, which indicates that the $\mathrm{NdFeB}$ element is well mixed. Element $\mathrm{O}$ is believed to originate from the polymer matrix overlying the initial $\mathrm{NdFeB}$ powder. In the addition of $4 \%$ PVB binder, the element Carbon (C) is more dominant than other elements. This indicates the presence of polymer in the $\mathrm{NdFeB}$ bonded magnet sample. The element of Boron (B) in the NdFeB compound is not visible because the amount is too small and the photon energy is low, making it difficult to detect by EDX detectors.

\subsection{Characterization of Magnetic Properties}

\section{A. Analysis of Magnetic Field Strength}

The value of the magnetic field strength of a sample can be obtained using a gaussmeter after being magnetized. The results of the magnetic field strength measurement on the $\mathrm{NdFeB}$ bonded magnet are shown in Figure 5, showing that the more addition of the polyvinyl butyral (PVB) binder composition to the $\mathrm{NdFeB}$ magnetic powder causes a decrease in the magnetic field strength. The highest magnetic field strength was obtained in the addition of $2 \%$ wt PVB binder of 1862.4 G. In the addition of $4 \%$ wt and $6 \%$ wt PVB binder, the magnetic field strength was almost the same at $1776.3 \mathrm{G}$ and $1771.7 \mathrm{G}$ but in the PVB binder $7 \%$ wt experienced a very drastic decrease in the magnetic field strength of $1546.4 \mathrm{G}$. The increase in the composition of the non-magnetic material (polymer matrix) certainly caused a reduction in the composition of the $\mathrm{NdFeB}$ magnetic powder, this resulted in a decrease in the value of the magnetic field strength in the NdFeB bonded magnet sample [8-10]. 


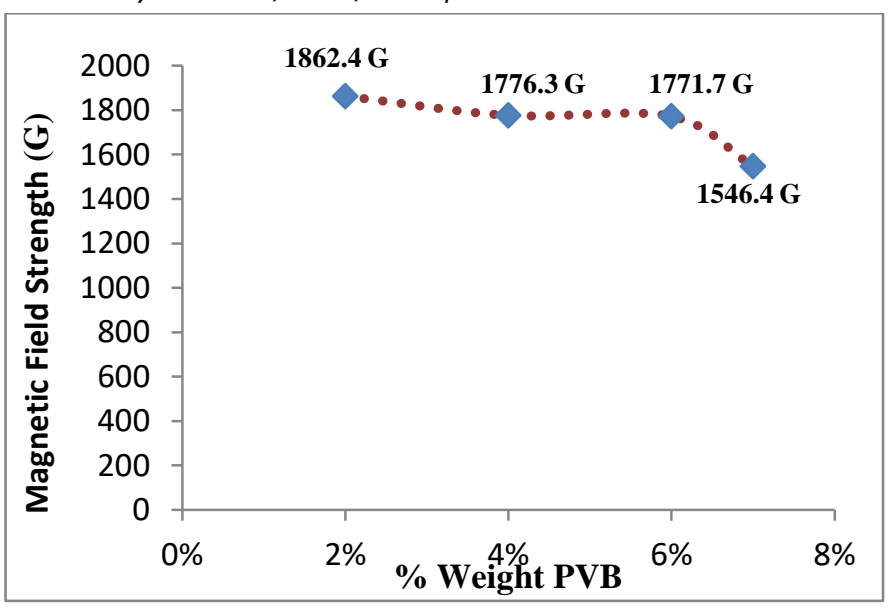

Figure 5. Graph of the relationship between the weight\% of Polyvinyl Butyral (PVB) to the value of the magnetic field strength in the $\mathrm{NdFeB}$ bonded magnet

\section{B. $\quad$ VSM (Vibrating Sample Magnetometer) Analysis}

VSM (Vibrating Sample Magnetometer) is a type of equipment used to study the magnetic properties of materials. VSM testing is carried out to obtain information about the magnitude of magnetic properties as a result of changes in the external magnetic field which is depicted in the hysteresis curve equipped with the value of remanent induction $(\mathrm{Br})$ and coercive force $(\mathrm{Hc})$.

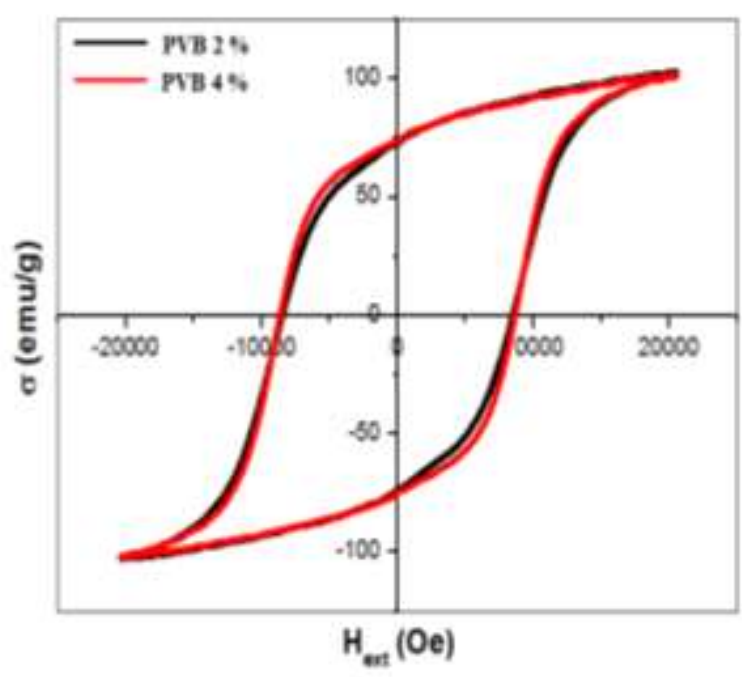

Figure 6. Hysteresis curve for NdFeB bonded magnet with 2\% PVB and 4\% PVB composition Figure 6 shows the results of the magnetic properties test by VSM on the NdFeB bonded magnet sample. To find out the value of magnetic properties from the results of the hysteresis curve in Figure 6 is shown in Table 7. 
Table 7. Data on the results of magnetic properties testing on $\mathrm{NdFeB}$ bonded magnets for $2 \%$

PVB and $4 \%$ PVB

\begin{tabular}{ccccc}
\hline $\begin{array}{c}\text { \% berat } \\
\text { Binder }\end{array}$ & $\begin{array}{c}\mathrm{Mr} \\
(\mathrm{emu} / \mathrm{g})\end{array}$ & $\begin{array}{c}\mathrm{Ms} \\
(\mathrm{emu} / \mathrm{g})\end{array}$ & $\begin{array}{c}\mathrm{Hc} \\
(\mathrm{KOe})\end{array}$ & $\begin{array}{c}\mathrm{BH}_{\max } \\
(\mathrm{MGOe})\end{array}$ \\
\hline PVB 2\% & 72.86 & 103 & 8.490 & 5.1 \\
PVB 4\% & 73.84 & 102 & 8.647 & 5.2 \\
\hline
\end{tabular}

From the hysteresis curve and Table 7 shows that the bonded magnet $\mathrm{NdFeB}$ to the polymer matrix (PVB) is a hard magnetic material (permanent magnet). Hard magnetic materials (permanent magnets) are characterized by large hysteresis curves and high coercivity (Hc) values above 200 Oe. Coercivity $(\mathrm{Hc})$ is the amount of magnetic field required to negate the magnetism of a material. The strength of the magnet (magnetic field) is determined by the amount of remanence (Mr) of a material. Remaining $(\mathrm{Mr})$ is the residual magnet present in the material after the influence of the external magnetic field is eliminated.

The results of the hysteresis curve above show that the coercivity $(\mathrm{Hc})$ and remanence $(\mathrm{Br})$ values were greater in the addition of $4 \%$ polyvinyl butyral binder of $8.67 \mathrm{KOe}$ and 73.84 emu.g ${ }^{-1}$. The maximum product energy value (BHmax) was also higher in the addition of $4 \%$ polyvinyl butyral binder than the $2 \%$ which was 5.2 MGOe. The value of the maximum energy product is generated from the maximum value of the multiplication between $\mathrm{B}$ and $\mathrm{H}$ in the second quadrant of the hysteresis curve. Based on the results of the hysteresis curve above, the higher the remanence value, the greater the coercive force and hysteresis curve (fat) and the greater the product energy.

\section{Conclusion}

1. The NdFeB Bonded Magnet has been successfully made using a Polyvinyl Butyral (PVB) binder with the Hydrolic Press method, where the addition of a variety of polymer compositions to the $\mathrm{NdFeB}$ magnetic powder greatly affects the density and strength of the magnetic field.

2. In the bonded magnet $\mathrm{NdFeB}$ with Polyvinyl butyral (PVB) binder, the characteristic density value is $5.66 \mathrm{~g} . \mathrm{cm}^{-3}$ and the magnetic field strength is $1862.4 \mathrm{G}$ with the addition of $2 \%$ PVB.

3. Testing of magnetic properties by VSM which produces a hysteresis curve, obtained high coercivity $(\mathrm{Hc})$, remanence $(\mathrm{Br})$ and maximum product energy (BHmax) values in the addition of $2 \%$ polyvinyl butyral binder of $8.490 \mathrm{KOe}, 72.86 \mathrm{emu} . \mathrm{g}^{-1}$ and $5.1 \mathrm{MGOe}$. The higher the remanence value, the greater the coercive force and hysteresis curve (fat) and the greater the energy value of the product. 
[1] E. Yulianti and Mujamilah, "Sifat Magnetik Bahan Komposit Berbasis Serbuk Magnet NdFeB Hasil Milling dan Polimer Termoplastik LLDPE," Jurnal Sains Materi Indonesia, vol. 6, no. 2, pp. 36-41, 2005.

[2] P. Sardjono, A. Sukarto, P. Sebayang, M. R. T. Siregar, Nanang S, A. Manaf, Ridwan and S. Evan, "Inovasi Teknologi Pembuatan Magnet Permanen untuk Membangun Industri Magnet Nasional," in Prosiding InSINas 2012, pp. 102-108, 2012.

[3] J. Fraden, Handbook of Modern Sensors: Physics, Designs and Applications $5^{\text {th }}$ Edition, New York: Springer International Publishing, 2016.

[4] W. Z. Qin, J. He and W. T. Zhao, "Research on Compound Powder of Bonded NdFeB Magnets from Injection Molding," Advanced Materials Research, vol. 228-229, pp. 841846, 2011.

[5] J. Stajic-Trosic, M. Stijepovic, J. Stevanovic, R. Aleksic and A. Grujic, "Magnetic and Dynamic Mechanical Properties of Nd-Fe-B Composite Materials with Polymer Matrix," in Metal, Ceramic and Polymeric Composites for Various Uses, J. Cuppoletti, Ed., London: IntechOpen Limited, 2011.

[6] S. R. Sultan, N. J. Salah and A. A. A. Razak, "Improve the Performance of Epoxy Resin and Poly (Vinyl Butyral) as an Aluminum Metal Adhesion," Journal of Techniques, vol. 23, no. 1, pp. 35-45, 2010.

[7] M. Drak, B. Ziebowicz and L. A. Dobrzański, "Manufacturing of Hard Magnetic Composite Materials Nd-Fe-B," Journal of Achievements in Materials and Manufacturing Engineering, vol. 31, no. 1, pp. 91-96, 2008.

[8] D. Aryanto, C. Kurniawan and T. Sudiro, "Modifikasi Serbuk Bonded PrFeB dan Karaterisasinya," In Prosiding Pertemuan Ilmiah XXVIII Himpunan Fisika Indonesia Jateng \& DIY: Peran Fisika dalam Mendukung Pembangunan Berkelanjutan, Yogyakarta, 26 April 2014, D. Rosana, et al, Eds. Yogyakarta: Himpunan Fisika Indonesia Cabang Jateng \& DIY, 2014, pp. 207-210.

[9] T. Havwini, "Pengaruh Komposisi Bakelit dan Resin Epoksi pada Pembuatan Bonded Magnet Permanen Pr-Fe-B,” B. S. thesis, Universitas Sumatera Utara, Medan, 2013.

[10] O. Gutfleisch, "Controlling the Properties of High Energy Density Permanent Magnetic Materials by Different Processing Routes," Journal of Physics D: Applied Physics, vol. 33, no. 17, pp.R157-R172, 2000. 